\title{
ГЕНЕТИЧЕСКАЯ ДИФФЕРЕНЦИАЦИЯ ИНДЕЕК РАЗНЫХ ПОРОД ПО МИКРОСАТЕЛЛИТНЫМ МАРКЕРАМ
}

\author{
В.И. ФИСИНИН ${ }^{1}$, М.И. СЕЛИОНОВА 2 ${ }^{\star}$, Д.А. КОВАЛЕВ 3 , \\ Л.А. ШИНКАРЕНКО
}

Одна из тенденций современного индустриального сельского хозяйства - сокращение генетических ресурсов пород животных и птицы. В программах по их сохранению важная роль отводится изучению генетических особенностей, в том числе с использованием микросателлитных локусов. При реализации международного проекта по изучению генетического биоразнообразия домашних животных (Global Project for the Measurement of Domestic Animal Genetic Diversity, MoDAD) по микросателлитным маркерам было исследовано 50 популяций разных видов птицы. Изучение биоразнообразия индеек на первоначальном этапе проводилось с использованием микросателлитных локусов курицы (Gallus gallus), затем были установлены информативные локусы для генома индеек (Meleagris gallopavo). Накоплены данные о генетических профилях, сходстве, различии и межпородной дифференциации пород индеек, разводимых в США, Италии, Венгрии и других странах. В настоящей работе впервые установлено генетическое взаимоотношение между породами индеек российской селекции и генофондной популяции университета Миннесоты на основе микросателлитных маркеров. Показано, что величина генетических дистанций между породами во многом определяется их происхождением, ареалом разведения, а также вкладом генофонда одних пород при создании и совершенствовании продуктивных качеств других. Цель работы - изучить генетическое разнообразие и межпородную дифференциацию индеек российской и зарубежной селекции с использованием микросателлитных локусов. Работа выполнялась на Северо-Кавказской зональной опытной станции по птицеводству в 2019 году. У 30 особей каждой из семи пород индеек (Meleagris gallopavo) отечественной селекции (белой широкогрудой, BSH; бронзовой северокавказской, BrSK; белой северокавказской, BeSK; серебристой северокавказской, SSK; московской белой, MB; черной тихорецкой, СHT; узбекской палевой, UP) были отобраны образцы крови. ДНК выделяли в соответствии с протоколом к коммерческому набору АмплиПрайм ДНК-сорб-В («ИнтерЛабСервис», Россия). Количество и качество выделенной ДНК контролировали с использованием спектрофотометра NanoDrop 2000 («Thermo Scientific», США) стандартным спектрофотометрическим методом. Генотипирование проводили по 12 микросателлитным локусам MNT9-MNT20. Для сравнения с генотипами индеек отечественных пород использовали описанные генотипы индеек (АМ) генофондной фермы университета Миннесоты (Nicholas Turkey Breeding Farms). Вычисляли среднее число и число эффективных аллелей на локус $(\mathrm{Na}, \mathrm{Ne})$, степень наблюдаемой и ожидаемой гетерозиготности $\left(\mathrm{H}_{0}, \mathrm{He}_{\mathrm{e}}\right.$, индекс Шеннона (I). Генетическую структуру популяций оценивали на основании значений $F_{\text {st }}$ и генетических дистанций по М. Nei. Для построения филогенетического дерева применяли метод ближайшего соседа (Neighbor Joining Method). Российские породы индеек и популяция АМ характеризовались низким генетическим разнообразием. Число выявленных аллелей в локусах микросаттеллитов в целом по породной выборке варьировало от 1 до 4, число аллелей на один локус колебалось от 1,0 до 1,83. Наименьшее генетическое различие установлено между породами МВ и BSH. Породы BeSK, SSK и BrSK сформировали отдельный узел, при этом наибольшее генетическое удаление проявляла BrSK, образуя наибольшую по генетическому расстоянию ветвь. В отдельные ветви на относительно равном удалении выделились породы СНT, UP и популяция АМ. Таким образом, получено подтверждение, что генофонд исследованных пород и популяций домашних индеек характеризуется незначительным генетическим разнообразием по сравнению с генофондом других видов сельскохозяйственных животных.

Ключевые слова: породы индеек, микросателлиты, филогенетический анализ, генетическое разнообразие.

Одна из проблем современного индустриального сельского хозяйства - сокращение национальных генетических ресурсов пород сельскохозяйственных животных и птицы, снижение их генетического разнообразия. Подчас создается угроза не только сокращения, но и полной утраты уникальных особо ценных генофондов. Приоритетность снижения потерь генетических ресурсов, сохранения многообразия существующих локальных пород, региональных групп, типов животных и птицы, способных давать продукцию в различных условиях разведения и обеспечивающих устойчивое развитие животноводства, подтверждена международной кон- 
венцией о биологическом разнообразии (1).

Важный аспектом в разработке программ по сохранению пород сельскохозяйственных животных - изучение их генетических особенностей. Для оценки таких особенностей, а также паспортизации пород широко применяются мульти- и монолокусные ДНК маркеры, или микросателлиты и однонуклеотидные полиморфизмы (ОНП) (2).

Микросателлиты, как правило, высокополиморфны и включают множество аллелей на один локус. Рекомендации ФАО (Food and Agriculture Organization, FAO) по выбору микросателлитных локусов при исследовании различных видов сельскохозяйственных животных опираются на перечень (DAD-IS библиотека, http://www.fao.org/dad-is/), paзработанный группой ISAG-FAO по генетическому разнообразию. Микросателлиты признаются информативными для анализа происхождения и картирования локусов количественных признаков (quantitative trait loci, QTL) (3, 4). В то же время с развитием технологий молекулярного тестирования все большее признание и преимущество перед ними получает анализ однонуклеодидных замен (single nucleotide polymorphism, SNP) с использованием микроматриц, или чипов (5).

Для сохранения и рационального использования генетических ресурсов сельскохозяйственных животных и птицы ФАО был осуществлен широкомасштабный проект по анализу их генетического разнообразия (Global Project for the Measurement of Domestic Animal Genetic Diversity, MoDAD) (6). По микросателлитным локусам изучено более 50 популяций разных видов птицы (7-9).

Исследование микросаттелитных локусов индеек (Meleagris gallopavo) началось в 2000-х годах, при этом использовали микросателлитные панели, разработанные для кур (Gallus gallus). К. Reed с соавт. (10) для работы на индейках применили 520 куриных микросателлитных маркеров. В 280 случаях (54 \%) были получены продукты амплификации, большинство из которых оказались или близкими по размеру с фрагментами, амплифицированными с ДНК курицы, или полностью совпадали. При оценке информативности для генетического картирования индейки был определен аллельный полиморфизм 57 из 280 амплифицированных участков. В общей сложности 20 из 57 маркеров (35\%) оказались полиморфными (в среднем 1,4 аллель на локус). Сделано заключение, что для картирования генома индейки могут использоваться около 20 \% микросателлитных локусов курицы (10).

Куриные микросателлиты применяли для изучения генофонда индеек пород брианзоло, колли евджений и итальянская черная (brianzolo, colli euganei, nero d'Italia). Из 31 локуса информативными оказались 22. При этом 12 локусов (ADL0112, LEI0192, LEI0234, MCW0014, MCW0016, MCW0037, MCW0067, MCW0098, MCW0103, MCW0111, MCW0165, MCW0183) изучали в одиночных ПЦР, 10 локусов - с помощью мультиплексных панелей (Multiplex Master Mix 1 - ADL0268, ADL0278, LEI0094, MCW0216, MCW0248; Master Mix 2-MCW0034, MCW0069, MCW0081, MCW0222, MCW0295). В девяти маркерах (LEI0166, MCW0020, MCW0078, MCW0080, MCW0104, MCW0123, MCW0248, MCW0284, MCW0330) амплифицированных участков ДНК не обнаружили (11). Восемь микросателлитных маркеров кур Gallus gallus (MCW0111, MCW0067, LEI0104, MCW0123, MCW0081, MCW0069, MCW0104, MCW0183), из которых семь оказались полиморфными, применялись для изучения генофонда индеек BUT (British United Turkeys) BIG6 и BIG10 (12, 13).

В дальнейшем использовали 772 микросателлитных маркера, раз- 
работанных для трех видов птиц - курицы, перепелки и индейки. В peзультате скрининга для исследования аллельного полиморфизма и построения генетической карты индеек отобрали 410 микросателлитных локусов $(53,1 \%)$. На специально созданной генетической модели (семье), включающей прямых родственников трех поколений (224 особи), проводили генотипирование по отобранным локусам. Из 410 маркеров 109 (26,6 \%) оказались полиморфными (2,3 аллеля на маркер). Более высокий полиморфизм $(61,1 \%)$ выявили при использовании специфичных для индеек маркеров. При применении маркеров, специфичных для перепелов и курицы, полиморфность составила соответственно 33,3 и 22,7 \%. Авторы пришли к заключению, что перепелиные и куриные микросателлитные локусы могут быть применены для построения сравнительной генетической карты индеек (14).

Следующим этапом стала интеграция данных, полученных в двух научных центрах - Рослинском институте (the Roslin Institute, Эдинбург, Шотландия) и университете Миннесоты (the University of Minnesota, Миннеаполис, США) (15). На индейках экспериментальной фермы Миннесотского университета из 279 микросателлитных маркеров, выявленных и исследованных в Рослинском институте, скрининговым исследованиям подвергли 240. Из них 89 оказались генетически информативными и использовались для генотипирования потомства F2. Анализ с применением пакета программ BLAST (Basic Local Alignment Search Tool) позволил унифицировать 483 нуклеотидные последовательности микросателлитов.

Также было выполнено BLAST выравнивание маркерных последовательностей геномов индейки и курицы. Выявлено 263 совпадения и 1700 последовательностей, имеющих высокую гомологию (15).

В совместной работе ученых из США и Турции проводился поиск информативных микросателлитных маркеров для изучения биоразнообразия индеек и создания унифицированной панели. На основе нуклеотидной библиотеки данных был осуществлен дизайн праймеров для 164 фрагментов генома индеек, содержащих микросателлиты. Выявлено 154 информативных генетических маркера, однако, по мнению авторов, этого недостаточно для общей панели (16).

Интерес к изучению генетического разнообразия индеек, в том числе для генетической паспортизации коммерческих пород, прежде всего продиктован тем, что производство мяса индейки в мире постоянно растет. Оно составляет 6,1 млн т в общемировом объеме мяса птицы, занимая второе место. Положительная динамика наблюдается и в России: по данным компания Agrifood Stratedges, рост производства мяса индейки в 2019 году по сравнению с 2007 составил 185 тыс. т (с 37 до 289 тыс. т, или в 7,8 раза), что характеризует этот сегмент рынка как наиболее перспективный и быстро растущий.

Россия имеет собственные генетические ресурсы в индейководстве: в реестре селекционных достижений зарегистрировано семь пород, три кросса и семь линий индеек отечественной селекции. Северо-Кавказская зональная опытная станция по птицеводству - не только правообладатель отечественного генофонда индеек, но и единственное в России предприятие, где ведется планомерная работа по созданию новых селекционных форм.

Впервые генетический профиль российских пород индеек по микросателлитным локусам был изучен в 2017 году. Численность в выборках исследованных пород колебалась от 9 до 15 особей, для оценки репрезентативности выборок использовали индекс Хантера-Гастона, кластерный 
анализ проводили методом UPGMA, дендрограмму строили с помощью компьютерной программы START 2. Было установлено, что наибольшую генетическую близость имели породы бронзовая северокавказская, белая северокавказская и белая широкогрудая, затем следовали черная тихорецкая, серебристая северокавказская и московская белая. Наиболее удаленной оказалась узбекская палевая порода (17). Однако сравнения генофонда отечественных пород индеек с генофондом импортной селекции при этом не проводили.

В настоящей работе на основе микросателлитных маркеров впервые установлены генетические взаимоотношения между породами индеек российской селекции и генофондной популяции университета Миннесоты. Показано, что величина генетических дистанций между породами во многом определяется их происхождением, ареалом разведения, а также вкладом генофонда одних пород при создании и совершенствовании продуктивных качеств других.

Цель работы - изучить генетическое разнообразие и межпородную дифференциацию индеек российской и зарубежной селекции с использованием микросателлитных локусов.

Методика. Работа выполнялась на Северо-Кавказской зональной опытной станции по птицеводству в 2019 году. У 30 особей каждой из семи пород индеек (Meleagris gallopavo) отечественной селекции (белой широкогрудой, BSH; бронзовой северокавказской, BrSK; белой северокавказской, BeSK; серебристой северокавказской, SSK; московской белой, MB; черной тихорецкой, СНT; узбекской палевой, UP) отбирали образцы крови из подкрыльцовой вены.

ДНК выделяли в соответствии с протоколом к коммерческому набору АмплиПрайм ДНК-сорб-В («ИнтерЛабСервис», Россия). Количество и качество выделенной ДНК контролировали с использованием спектрофотометра NanoDrop 2000 с («Thermo Scientific», США) стандартным спектрофотометрическим методом, расчет и визуализацию результата проводили в программе NanoDrop 2000, версия 1.4.2. Раствор сравнения ТЕ-буфер рН 7,8-8,2 (ФБУН Центральный научно-исследовательский институт эпидемиологии, Россия).

Генотипирование проводили по 12 микросателлитным локусам MNT9-MNT20 (18, 19). ПЦР осуществляли на амплификаторе T 100 («BioRad Laboratories, Inc.», США) в смеси конечного объема 20 мкл, содержащей из расчета на одну реакцию следующие реагенты: по 1 мкл прямого и обратного праймеров (ФКУЗ СтавНИПЧИ Роспотребнадзора, Россия), 2 мкл раствора дНТФ, 4 мкл РНК-элюента, 10 мкл ПЦР-смесь-2red («ИнтерЛабСервис», Россия) и 2 мкл проб ДНК. Режим амплификации был следующим: 15 мин при $95{ }^{\circ} \mathrm{C}$; 30 с при $95{ }^{\circ} \mathrm{C}, 30$ с при $58{ }^{\circ} \mathrm{C}$ (для локусов MNT10, MNT11, MNT20 - $\left.56{ }^{\circ} \mathrm{C}\right), 30$ с при $72{ }^{\circ} \mathrm{C}$ (35 циклов); 5 мин при $72{ }^{\circ} \mathrm{C}$.

С использованием станции Experion System («Bio-Rad Laboratories, Inc.», США) и набора реагентов для визуализации фрагментов ДНК Ехperion DNA 1K Analysis Kit («Bio-Rad Laboratories, Inc.», США) проводили капиллярный электрофорез.

Для сравнения с генотипами индеек отечественных пород использовали описанные генотипы индеек (AM) генофондной фермы университета Миннесоты (Nicholas Turkey Breeding Farms) $(18,19)$.

Среднее число аллелей и число эффективных аллелей на локус $(\mathrm{Na}$, $\mathrm{Ne})$, степень наблюдаемой и ожидаемой гетерозиготности $\left(\mathrm{H}_{\mathrm{o}}, \mathrm{H}_{\mathrm{e}}\right)$, индекс 
1. Последовательности праймеров, использованных в работе для генотипирования индеек (Meleagris gallopavo) по микросателлитным локусам

\begin{tabular}{|c|c|c|c|c|c|}
\hline \multirow{2}{*}{ Локус } & \multirow{2}{*}{ Номер в GenBank } & \multirow{2}{*}{ Последовательность } & \multicolumn{2}{|c|}{ Последовательность праймеров $\left(5^{\prime} \rightarrow 3^{\prime}\right)$} & \multirow{2}{*}{ Размер аллелей, п.н. } \\
\hline & & & прямой & обратный & \\
\hline MNT9 & AF482368 & (CA) 18 & TGGGAGTGGAAAGGTGAAAG & TTCTCCTCAGCTCAGCAACC & 164,168 \\
\hline MNT10 & AF482369 & $\begin{array}{l}\text { (TG) } 10+ \\
\text { (TTTG) } 5\end{array}$ & TTCCCAGTGCACTACCTGAAC & TGAACAGTGATTCCACTGAAGC & 67,78 \\
\hline MNT11 & AF482370 & (TG) 12 & TTTCTGACACAGGTACAAGGAAAC & GCCCTCGAGTATTAGCCACTC & 90 \\
\hline MNT12 & AF482371 & (TG) $14 \mathrm{imp}$ & AGGTGTTTTTGGGCAGTCTC & TGCAAGCACCATCTGCTAAG & 121,145 \\
\hline MNT13 & AF482372 & (TG) 20 & TTAGGGGATGCTGAACTGTG & GCGTAATTGGTGCTTTCTCC & $183,185,187,235$ \\
\hline MNT14 & AF482373 & (CA) 10 & AAACAGAACAACCTCAAGGACAG & GAATTGGGTTTGCATTTGAG & 177,181 \\
\hline MNT15 & AF482374 & (CA) 12 & TTGTTGCTGTTGTTTTTGTGG & TTTCTGTGCCTAAGCTTAATGTG & 188 \\
\hline MNT16 & AF482375 & $\begin{array}{l}\text { (TG) } 13+(\mathrm{TG}) 11 \\
+(\mathrm{TG}) 8+(\mathrm{TG}) 5\end{array}$ & TGTTTGCCTGCAATAAGCTG & GCACCCTCCCACTGACTG & $219,226,234$ \\
\hline MNT17 & AF482376 & $(\mathrm{TA}) 5+(\mathrm{CA}) 29$ & AGGAGCACCCAGCTCAAAG & GAGTAATACCAAGGAAAAGTGTGC & 181 \\
\hline MNT18 & AF482377 & (TG) 13 & GCAGGCACAGAGAGCTACG & CCAATGTTGAAGCAGGTGAG & $158,159,161,162$ \\
\hline MNT19 & AF482378 & (TG) 22 & GCAGGAGGCTCTGAGCTATG & TTATACGGAAGGCGGTTGAG & 224,250 \\
\hline MNT20 & AF482379 & (CA) 15 & TAACTGTCTGCCAGGTGGTG & GATCTCGGGTGGTGATTGC & 192,195 \\
\hline
\end{tabular}


Шеннона (I) определяли с использованием пакетов программ Microsoft Excel 2007, GenAIEx v 6.5 (20). Вычисляли средние $(M)$ и стандартные отклонения $( \pm \mathrm{SD})$. Генетическую структуру популяций оценивали на основании значений $\mathrm{F}_{\mathrm{st}}(21)$ и генетических дистанций по M. Nei (22). Для построения филогенетического дерева применяли метод ближайшего соседа (Neighbor Joining Method) с использованием программного обеспечения Structure 2.3 .4 (23).

Результаты. Для работы отобрали микросателлитные локусы, которые применялись при исследовании индеек генофондной фермы университета Миннесоты (NTBF) (табл. 1).

Анализ полученных данных позволил установить, что индейки российских пород и генофондной фермы университета Миннесоты характеризовались низким генетическим разнообразием. Число выявленных аллелей в локусах микросаттеллитов в целом по породной выборке варьировало от 1 до 4 (табл. 2).

2. Число аллелей в локусах микросателлитов у индеек (Meleagris gallopavo) отечественных пород (Северо-Кавказская зональная опытная станция по птицеводству, Ставропольский край, 2019 год) и популящии генофондной фермы университета Миннесоты (Nicholas Turkey Breeding Farms)

\begin{tabular}{|c|c|c|c|c|c|c|c|c|}
\hline \multirow{2}{*}{ Локус } & \multicolumn{8}{|c|}{ Порода } \\
\hline & BSH & BrSK & BeSK & SSK & MB & CHT & UP & AM \\
\hline MNT9 & 2 & 2 & 2 & 1 & 2 & 2 & 1 & 2 \\
\hline MNT10 & 1 & 1 & 1 & 2 & 2 & 1 & 1 & 1 \\
\hline MNT11 & 1 & 1 & 1 & 1 & 1 & 1 & 1 & 3 \\
\hline MNT12 & 2 & 2 & 2 & 1 & 2 & 1 & 1 & 1 \\
\hline MNT13 & 4 & 3 & 3 & 2 & 2 & 1 & 1 & 2 \\
\hline MNT14 & 2 & 1 & 1 & 1 & 2 & 1 & 1 & 2 \\
\hline MNT15 & 1 & 1 & 1 & 1 & 1 & 1 & 1 & 2 \\
\hline MNT16 & 2 & 2 & 2 & 1 & 1 & 2 & 1 & 2 \\
\hline MNT17 & 1 & 1 & 1 & 1 & 1 & 1 & 1 & 2 \\
\hline MNT18 & 3 & 2 & 2 & 1 & 3 & 1 & 1 & 1 \\
\hline MNT19 & 1 & 1 & 1 & 1 & 2 & 2 & 2 & 1 \\
\hline MNT20 & 2 & 1 & 1 & 1 & 2 & 2 & 2 & 2 \\
\hline
\end{tabular}

П р и м е ч а н и е. BSH - белая широкогрудая, BrSK - бронзовая северокавказская, BeSK - белая северокавказская, SSK - серебристая северокавказская, МВ - московская белая, СНТ - черная тихорецкая, UP - узбекская палевая породы, AM - популяция генофондной фермы университета Миннесоты (18, 19).

Среднее число аллелей (Na) на локус колебалось от 1,0 до 1,83, при этом наибольшим числом характеризовались породы $\mathrm{BSH}(1,83)$, MB $(1,75)$ и популяция АМ $(1,75)$. По одному аллелю на локус выявили в породах SSK и UP. Аналогичные закономерности наблюдались в отношении числа эффективных аллелей $(\mathrm{Ne})$ : наибольшее значение этого показателя было в породе BSH и популяции АМ $(1,58$ и 1,55), минимальное - в породах SSK и UP $(1,0)$, породы московская белая и черная тихорецкая занимали промежуточное положение $(1,30$ и 1,16$)$. Выявленное низкое число аллелей на микросателлитный локус у индеек российской селекции согласуется с данными зарубежных исследователей, которые указывают на невысокое генетическое разнообразие коммерческих пород индеек по сравнению с другими видами сельскохозяйственных животных и птицы, а также дикими популяциями индеек $(24,25)$.

Сопоставление значений ожидаемой и наблюдаемой гетерозиготности $\left(\mathrm{H}_{\mathrm{o}}-\mathrm{H}_{\mathrm{e}}\right)$ показало недостаток гетерозигот во всех изученных породах и популяции от 0,2 до 0,6 \%. О низком генетическом разнообразии свидетельствовал и информационный индекс Шеннона, который не превышал значения 0,50, а в породах SSK и UP был равен нулю (табл. 3).

Расчет генетический дистанций по М. Nei (табл. 4) и кластерный анализ с применением метода Neighbor Joining tree позволили получить графическое отображение филогенетического родства (рис.) между поро- 

университета Миннесоты.

3. Генетическое разнообразие индеек (Meleagris gallopavo) отечественных пород ( $n=30$, Северо-Кавказская зональная опытная станция по птицеводству, Ставропольский край, 2019 год) и популяции генофондной фермы университета Миннесоты (Nicholas Turkey Breeding Farms) по локусам микросателлитов $(M \pm \mathrm{SD})$

\begin{tabular}{l|c|c|c|c|c|c}
\hline \multicolumn{1}{c}{ Порода } & $\mathrm{Na}$ & $\mathrm{Ne}$ & $\mathrm{H}_{\mathrm{o}}$ & $\mathrm{H}_{\mathrm{e}}$ & $\mathrm{H}_{\mathrm{o}}-\mathrm{H}_{\mathrm{e}}$ & $\mathrm{I}$ \\
\hline BSH & $1,83 \pm 0,27$ & $1,58 \pm 0,19$ & $0,273 \pm 0,07$ & $0,279 \pm 0,07$ & $-0,006$ & $0,416 \pm 0,12$ \\
BrSK & $1,50 \pm 0,19$ & $1,07 \pm 0,03$ & $0,063 \pm 0,02$ & $0,065 \pm 0,02$ & $-0,002$ & $0,122 \pm 0,04$ \\
BeSK & $1,50 \pm 0,19$ & $1,43 \pm 0,18$ & $0,207 \pm 0,07$ & $0,212 \pm 0,07$ & $-0,005$ & $0,304 \pm 0,11$ \\
SSK & $1,00 \pm 0,01$ & $1,00 \pm 0,00$ & $0,000 \pm 0,00$ & $0,000 \pm 0,00$ & 0,000 & $0,000 \pm 0,00$ \\
MB & $1,75 \pm 0,17$ & $1,30 \pm 0,12$ & $0,189 \pm 0,05$ & $0,194 \pm 0,05$ & $-0,005$ & $0,312 \pm 0,08$ \\
CHT & $1,33 \pm 0,14$ & $1,16 \pm 0,08$ & $0,106 \pm 0,04$ & $0,111 \pm 0,04$ & 0,005 & $0,162 \pm 0,07$ \\
UP & $1,00 \pm 0,01$ & $1,00 \pm 0,00$ & $0,000 \pm 0,00$ & $0,000 \pm 0,00$ & 0,000 & $0,000 \pm 0,00$ \\
AM & $1,75 \pm 0,17$ & $1,55 \pm 0,15$ & $0,286 \pm 0,07$ & $0,291 \pm 0,07$ & 0,005 & $0,419 \pm 0,14$
\end{tabular}

П р и м е ч а н и е. BSH - белая широкогрудая, BrSK - бронзовая северокавказская, BeSK - белая северокавказская, SSK - серебристая северокавказская, МB - московская белая, СНT - черная тихорецкая, UP - узбекская палевая породы, АM - популяция генофондной фермы университета Миннесоты (18, 19); $\mathrm{Na}$ и $\mathrm{Ne}-$ среднее и эффективное число аллелей на локус, Но и $\mathrm{He}-$ наблюдаемая и ожидаемая гетерозиготность, I - индекс Шеннона.

4. Генетическая дифференциация индеек (Meleagris gallopavo) отечественных пород (Северо-Кавказская зональная опытная станция по птицеводству, Ставропольский край, 2019 год) и популящии генофондной фермы университета Миннесоты (Nicholas Turkey Breeding Farms)

\begin{tabular}{l|l|l|l|l|l|l|l|c}
\hline \multicolumn{1}{c}{ Порода } & BSH & BrSK & BeSK & SSK & MB & CHT & UP & AM \\
\hline BSH & 0,000 & 0,250 & 0,127 & 0,594 & 0,344 & 0,457 & 0,162 & 4,872 \\
BrSK & 0,346 & 0,000 & 0,046 & 0,425 & 0,493 & 0,430 & 0,461 & - \\
BeSK & 0,180 & 0,127 & 0,000 & 0,579 & 0,514 & 0,469 & 0,212 & - \\
SSK & 0,495 & 0,423 & 0,514 & 0,000 & 0,131 & 0,363 & 1,386 & - \\
MB & 0,300 & 0,467 & 0,443 & 0,178 & 0,000 & 0,228 & 0,760 & - \\
CHT & 0,392 & 0,431 & 0,415 & 0,502 & 0,267 & 0,000 & 0,762 & - \\
UP & 0,241 & 0,612 & 0,339 & 0,870 & 0,672 & 0,672 & 0,000 & 3,684 \\
AM & 0,600 & 0,728 & 0,643 & 0,735 & 0,633 & 0,705 & 0,723 & 0,000
\end{tabular}

П р и м е ч а н и е. BSH - белая широкогрудая, BrSK - бронзовая северокавказская, BeSK - белая северокавказская, SSK - серебристая северокавказская, МB - московская белая, СНT - черная тихорецкая, UP - узбекская палевая породы, АM - популяция генофондной фермы университета Миннесоты (18, 19). Над диагональю - генетические дистанции по M. Nei (22), под диагональю - значения Fst при парном сравнении. Прочерки означают отсутствие показателей.

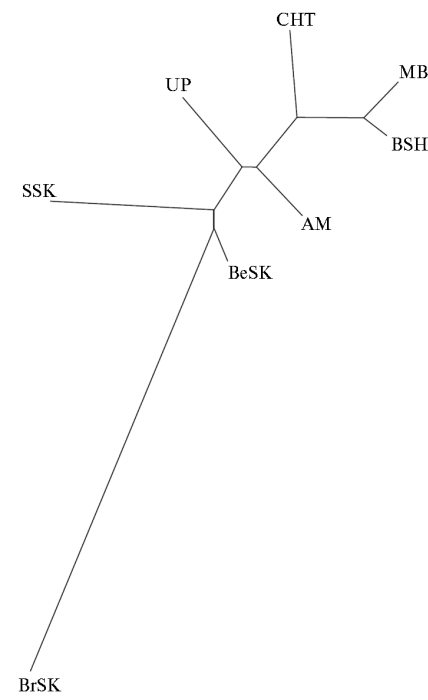

Генетические взаимосвязи индеек (Meleagris gallopavo) отечественных пород (Северо-Кавказская зональная опытная станция по птицеводству, Ставропольский край, 2019 год) и популяции генофондной фермы университета Миннесоты (Nicholas Turkey Breeding Farms) на основе генетических дистанций M. Nei (22): BSH - белая широкогрудая, BrSK - бронзовая северокавказская, BeSK - белая северокавказская, SSK - серебристая северокавказская, MB - московская белая, СНТ - черная тихорецкая, UP - узбекская палевая породы, АM - популяция генофондной фермы университета Миннесоты $(18,19)$.

Дендрограмма генетических дистанций демонстрировала наименьшее генетическое различие между породами МB и BSH. Породы $\mathrm{BeSK}$, SSK и BrSK образовали отдельный узел, при этом наибольшее генетическое удаление проявляла порода BrSK, как в этом узле, так и с другими породами, образуя наибольшую по генетическому расстоянию ветвь. Отдельные ветви на относительно равном удалении образовали попороды CHT, UP и популяция АM. Расположение пород индеек на дереве 
генетических дистанций, по-видимому, было обусловлено историей их создания. Белая широкогрудая - одна из старейших в мире пород, созданных в 1960-х годах в США. Она ведет генетическое происхождение от голландских белых индеек. На Северо-Кавказскую зональную станцию по птицеводству белая широкогрудая порода индеек, а именно четыре линии кpocca Hidon (A, В, C, Д), были завезены в 1980 году из Голландии. На базе линий В и D были отселекционированы родительские формы, сохранившиеся в чистоте до настоящего времени. Образцы их ДНК были использованы в настоящем исследовании. Московская белая порода создавалась в Московской области. На первоначальном этапе были использованы местные белые индейки и белтсвиллские индейки, на заключительном - белые голландские индейки. То есть генофонд белых индеек длительно использовался при создании пород белой широкогрудой и белой московской, что и обусловило их близкое расположение на дереве генетических расстояний.

Первую отечественную породу индеек - бронзовую северокавказскую вывели в 1950-1960-х годах скрещиванием местных аборигенных индеек с производителями бронзовой и бронзовой широкогрудой пород. Вторая отечественная порода - белая северокавказская была создана в 1970-1980-е годах посредством скрещивания аборигенных бронзовых северокавказских индеек с самцами белой широкогрудой породы английского происхождения. При выведении серебристой северокавказской породы, которая была официально признана в 2008 году, популяция палевых узбекских индеек на первых этапах улучшалась белой широкогрудой породой, преимущественно самцами линии О4 материнского типа, с целью повышения воспроизводства и мясной продуктивности. На заключительном этапе создания породы особи с разной долей генофонда белой широкогрудой разводились «в себе» при жесткой выбраковке не соответствующих требованиям фенотипов. Следовательно, белая северокавказская и серебристая северокавказская породы создавались при использовании генофонда белой широкогрудой, что, по-видимому, определило их большую генетическую близость между собой и некоторую удаленность от бронзовой северокавказской, которая создавалась исключительно с использованием пород бронзового оперения. Возможно, на образование общего узла бронзовой, белой и серебристой северокавказской породами повлияло и то, что все они создавались в Северо-Кавказском регионе. Однотипные факторы среды обитания, по-видимому, способствовали отбору близких генотипов.

Генетическая удаленность пород черная тихорецкая и узбекская палевая объясняется тем, что они создавались в большей степени при использовании популяций местных индеек. Узбекская палевая порода выводилась на основе узбекских бронзовых индеек, которые точечно улучшались белой широкогрудой породой. Использование белой широкогрудой породы при выведении узбекской палевой должно было повлиять на их генетическую близость. Однако черная тихорецкая порода оказалась ближе к породам белая широкогрудая и московская белая. Можно предположить, что значительная географическая удаленность ареала создания узбекской палевой породы обусловила большее генетическое различие с московской и белой широкогрудой породами, которые, как и черная тихорецкая, создавались в Северо-Кавказском регионе.

Определенную генетическую удаленность от российских пород проявляла популяция индеек генофондной фермы университета Миннесоты. Однако эта удаленность оказалась не столь выраженной, как ожидалось. Вероятно, генофонд популяции АМ включает как генофонд пород с 
бронзовым оперением, так и генофонд наиболее распространенной во всем мире белой широкогрудой породы, что определяет ее равную удаленность от изученных отечественных пород индеек.

Полученные в настоящем исследовании данные во многом совпадают с результатами В.И. Фисинина с соавт. (17). Построение дендрограммы на основе генетических дистанций с использованием тех же микросателлитных локусов, но на меньшей по объему выборке и с применением программы START 2 распределило изученные породы в два кластера. Первый кластер был образован частью генотипов белой широкогрудой и всеми генотипами породы узбекская палевая, второй - двумя крупными подкластерами. Первый подкластер сформировали генотипы пород бронзовая северокавказская, белая северокавказская и белая широкогрудая, второй - генотипами пород черная тихорецкая, серебристая северокавказская и московская белая (17). В указанном выше и в настоящем исследовании наиболее близкими оказались породы белая широкогрудая и московская белая, белая северокавказская и серебристая северокавказская, большее генетическое удаление проявляли черная тихорецкая и узбекская палевая. Использование в представляемой работе большего числа особей и метода ближайшего соседа в программе Structure 2.3.4 позволили выявить более значительную генетическую дифференциацию бронзовой северокавказской породы.

В другом исследовании, также выполненном на Северо-Кавказской зональной опытной станции по птицеводству, с помощью метода ДНКфингерпринтинга было показано, что наиболее близки породы бронзовая северокавказская и белая северокавказская, затем следовали серебристая северокавказская и узбекская палевая. Значительную генетическую удаленность от пород белой широкогрудой, белой северокавказской, серебристой северокавказской, бронзовой северокавказской и узбекской палевой проявляла черная тихорецкая (26).

Многие авторы указывают, что основными факторами, влияющими на степень генетической дифференциации домашних пород и диких популяций индеек, становятся использование генофонда одних пород при создании других и географическая местность их разведения. При этом ученые единодушны во мнении, что геном индеек значительно менее разнообразен по сравнению с геномом других видов сельскохозяйственных животных и птицы.

E.K. Latch с соавт. (24) исследовали дикую восточную (M. gallopavo silvestris) и домашнюю индейку (M. gallopavo), используя семь микросателлитных маркеров. Число аллелей на локус варьировало от 5 до 15, при этом домашние индейки по сравнению с восточными дикими характеризовались достоверно меньшими числом аллелей на локус и общей гетерозиготностью.

D. Kamara c coaвт. (27) изучали генетическую дифференциацию между коммерческими и некоммерческими породами индеек - наррагансетской, бурбонской красной, синевато-серой, испанской черной и королевской пальмовой (Narra-gansett, Bourbon Red, Blue Slate, Spanish Black и Royal Palm) из генофондной коллекции фермы колледжа Вирджиния по 10 микросателлитным локусам (RHT0009, RHT0011, RHT0024, RHT0095, RHT0131, RHT0216, RHT0294, TUM16, TUM20, ADL0023). C помощью филогенетического анализа установлено, что наррагансетская, бурбонская красная и синевато-серая породы имели большее генетическое сходство с коммерческими породами, чем испанская черная и королевская пальмовая (27). Аналогичные данные для этих пород были получены с другими гене- 
тическими маркерными системами (SNP и фрагменты ДНК случайных последовательностей - random amplification of polymorphic DNA, RAPD) (28). S. Kusza c соавт. (25) провели четкую генетическую дифференциацию между венгерской бронзовой и белой широкогрудой породами индеек на основе 15 микросателлитных локусов. Венгерская бронзовая порода характеризовалась большей полиморфностью (среднее число аллелей на локус $3,20)$, чем белая широкогрудая (среднее число аллелей на локус 2,77).

K.Е. Mock с соавт. (29) использовали микросателлитные маркеры и митохондриальную ДНК в наиболее изменчивой ее части для исследования генетических взаимоотношений между дикими популяциями индеек. Они изучили 24 популяции шести подвидов диких индеек: семь - Рио Гранде (Rio Grande, M. gallopavo intermedia), шесть - восточной индейки (M. gallopavo silvestris), три - Флорида (Florida, M. gallopavo osceola), пять Мерриам (Merriam's, M. gallopavo merriami), три - Гулда (Gould's, M. gallopavo mexicana). Авторы установили соответствие современного разделения подвидов дикой индейки, основанного на морфологическом описании, их генетическим характеристикам, за исключением восточной индейки и Флорида, которые не обнаруживали генетических различий. В популяциях Мерриам и Рио-Гранде выявлена положительная связь между генетическим и географическим расстоянием, тогда как в популяциях восточной индейки такой зависимости не обнаружено.

Для получения более полных сведений о генетическом разнообразии пород и линий индеек M.L. Aslam с соавт. (30) использовали более современный и информативный метод - полногеномное секвенирование. В результате сканирования генома 32 индеек из разных популяций было выявлено 5,49 млн SNP по отношению к описанному референсному геному индейки (UMD 2.01), который составляет 1,1 млрд оснований $(31,32)$. Гетерозиготность особей варьировала от 0,17 до 2,73 SNP, а по всей выборке колебалась от 0,73 до 1,64 SNP на тысячу пар нуклеотидов. Авторы пришли к выводу, что исследованные коммерческие породы и линии индеек имеют общее происхождение, при этом генетической основой при их выведении были дикие формы индеек, которые характеризуются более высокой гетерозиготностью. Также авторы подчеркивают, что геном индеек в сравнении с геномом других видов сельскохозяйственных животных и птицы характеризуется значительно большей консервативностью.

Таким образом, показано генетическое своеобразие и отличия генотипов пород индеек селекционно-генетического центра по разведению и сохранению генофонда отечественных пород индеек в сравнении с популяцией индеек генофондной фермы университета Миннесоты. Наименьшие генетические различия установлены между породами московская белая и белая широкогрудая, белая северокавказская и серебристая северокавказская. Породы черная тихорецкая и узбекская палевая, а также популяция индеек генофондной фермы университета Миннесоты проявляли большую генетическую удаленность как от указанных выше пород, так и между собой. Наибольшую генетическую дифференциацию демонстрировала порода бронзовая северокавказская. Внутрипородные особенности и межпородная дифференциация семи российских пород индеек по микросателлитным маркерам ДНК в значительной степени отражают историю их создания и совершенствования. Анализ числа аллелей на локус позволил подтвердить выявленную другими исследователями закономерность, согласно которой генофонд пород и популяций домашних индеек характеризуется незначительным генетическим разнообразием. Для дальнейшего 
рационального использования генофонда отечественных пород индеек, а также получения новой информации об их генетических особенностях и месте в генетической дифференциации среди других пород индеек, разводимых в мире, целесообразно использовать дополнительные методы и современные маркеры генетического анализа, такие как секвенирование SNP и MLST.

\author{
${ }_{1}^{1}$ ФНЦ Всероссийский научно-исследовательский \\ и технологический институт птицеводства РАН, \\ 141311 Россия, Московская обл., г. Сергиев Посад, ул. Птицеградская, 10, \\ e-mail: fisinin@land.ru; \\ 2ФГБОУ ВПО Российский государственный \\ аграрный университет-МСХА им. К.А. Тимирязева, \\ 127550 Россия, г. Москва, ул. Тимирязевская, 49, \\ e-mail: m_selin@mail.ru $\square$; \\ ${ }_{3}^{3}$ Федеральное казенное учреждение здравоохранения \\ Ставропольский научно-исследовательский противочумный \\ институт Роспотребнадзора, \\ 355005 Россия, г. Ставрополь, ул. Советская, 13-15, \\ e-mail: kovalev_da.stv@list.ru; \\ ${ }^{4}$ Северо-Кавказская зональная опытная станция по птице- \\ водству - филиал ФГБНУ ФНЦ Всероссийский \\ научно-исследовательский и технологический институт \\ птицеводства РАН, \\ 357812 Россия, Ставропольский край, Георгиевский р-н, с. Обильное, \\ e-mail: skzospzooteh@yandex.ru
}

Поступила в редакцию 26 апреля 2021 года

Sel'skokhozyaistvennaya biologiya [Agricultural Biology], 2021, V. 56, № 4, pp. 651-663

\title{
GENETIC DIFFERENTIATION OF TURKEY BREEDS WITH MICROSATELLITE MARKERS
}

\author{
V.I. Fisinin', M.I. Selionova ${ }^{\bowtie}$, D.A. Kovalev ${ }^{3}$, L.A. Shinkarenko ${ }^{4}$
}

\begin{abstract}
${ }^{1}$ Federal Scientific Center All-Russian Research and Technological Poultry Institute RAS, 10, ul. Ptitsegradskaya, Sergiev Posad, Moscow Province, 141311 Russia, e-mail fisinin@land.ru;

${ }^{2}$ Russian State Agrarian University - Timiryazev Moscow Agricultural Academy, 49, ul. Timiryazevskaya, Moscow, 127550 Russia, e-mail m_selin@mail.ru ( $₫$ corresponding author);

${ }^{3}$ Stavropol Anti-Plague Institute of Rospotrebnadzor, 13-15, ul. Sovetskaya, Stavropol, 355005 Russia, e-mail kovalev_da.stv@list.ru;

${ }^{4}$ North Caucasian Zonal Experimental Station for Poultry Breeding - Branch of the Federal Scientific Center AllRussian Research and Technological Poultry Institute RAS, s. Obil'noe, Georgievskii District, Stavropol Krai, 357812 Russia, e-mail skzospzooteh@yandex.ru
\end{abstract}

ORCID:

Fisinin V.I. orcid.org/0000-0003-0081-6336 Selionova M.I. orcid.org/0000-0002-9501-8080

The authors declare no conflict of interests

Received April 26, 2021

Kovalev D.A. orcid.org/0000-0002-9366-5647

Shinkarenko L.A. orcid.org/0000-0003-4959-5415

doi: 10.15389/agrobiology.2021.4.651eng

\section{Abstract}

One of the trends of modern industrial agriculture is the reduction of breed genetic recourses in farm animals and poultry. Current programs on maintenance of farm animals breeds are giving great attention to the genetic studies, including the use of microsatellite loci. The microsatellite analysis is one of the informative and accessible methods. During the implementation of the Global Project for the Measurement of Domestic Animal Genetic Diversity (MoDAD), 50 populations of different poultry species were studied using microsatellite markers. The works on biodiversity in turkeys initially involved chicken microsatellite loci (Gallus gallus), then informative loci were established for the genome of turkeys (Meleagris gallopavo). Data on genetic profiles, similarities, differences, and interbreed differentiation of turkeys breeds bred in the USA, Italy, Hungary and other countries have been accumulated. In the present work, the genetic relationship between the Russian turkey breeds and the turkey gene pool population of the University of Minnesota based on microsatellite markers was established for the first time. The obtained data indicate that the genetic distances between breeds is largely determined by their origin, breeding range, and the contribution of the gene pool of some breeds in creating and improving the productive qualities of other breeds. 
Our purpose was to study genetic diversity and interbreeding differentiation of turkeys of Russian and foreign breeding using microsatellite loci. The research was performed at the North Caucasus zonal experimental station for poultry farming in 2019. Blood samples were taken from 30 individuals of each of seven turkey breeds (Meleagris gallopavo) of the Russian selection (Belaya shirokogrudaya, BSH; Bronzovaya Severokavkazskaya, BrSK; Belaya Severokavkazskaya, BeSK; Serebristaya Severokavkazskaya, SSK; Moscowskaya Belaya, MB; Chernaya Tikhoretskaya, CHT; Uzbekskaya palevaya, UP). DNA was isolated according to the protocol for the commercial AmpliPrime DNA-sorb-B kit (InterLabService, Russia). The amount and quality of isolated DNA were assayed using a standard spectrophotometric method (a NanoDrop 2000 spectrophotometer, Thermo Scientific, USA). Genotyping was performed for 12 microsatellite loci (MNT9-MNT20). The described genotypes of turkeys gene pool farm (AM) (Nicholas Turkey Breeding Farms) of the University of Minnesota were used for comparison with the genotypes of turkeys of Russian breeds. The average number and number of effective alleles per locus $(\mathrm{Na}, \mathrm{Ne})$, the degree of observed and expected heterozygosity $\left(\mathrm{N}_{\mathrm{o}}, \mathrm{N}_{\mathrm{e}}\right)$, and Shannon index (I) were determined. The genetic structure of populations was assessed based on the FsT values and genetic distances according to M. Nei. The Neighbor Joining Method was used to construct the phylogenetic tree. It was shown that low genetic diversity is characteristic of both Russian breeds of turkeys and the AM population. The number of identified alleles in the microsatellite loci as a whole in the breed sample varied from 1 to 4 , the average number of alleles per locus ranged from 1.0 to 1.83 . The least genetic difference occurred between the MB and BSH breeds. The BeSK, SSK, and BrSK breeds formed a separate node, with BrSK exhibiting the greatest genetic distance, forming the largest branch by genetic distance. Separate branches at relatively equal distances formed the breeds CHT, UP, and AM population. Thus, our findings confirm an insignificant genetic diversity of the gene pool of the studied Russian turkeys' breeds and populations as compared to the gene pool of other species of farm animals.

Keywords: turkey breeds, microsatellites, phylogenetic analysis, genetic diversity.

\section{REFERENCES}

1. Stolpovskii Yu.A., Zakharov-Gezekhus I.A. Vavilovskii zhurnal genetiki i selektsii, 2017, 21(4): 477-486 (doi: 10.18699/VJ17.266) (in Russ.).

2. Jarne P., Lagoda P.J.L. Microsatellites, from molecules to populations and back. Trends in Ecology \& Evolution, 1996, 11(10): 424-429 (doi: 10.1016/0169-5347(96)10049-5).

3. Gholizadeh M., Mianji G.R. Use of microsatellite markers in poultry research. International Journal of Poultry Science, 2007, 6(2): 145-153 (doi: 10.3923/ijps.2007.145.153).

4. Putman A.I., Carbone I. Challenges in analysis and interpretation of microsatellite data for population genetic studies. Ecology Evolution, 2014, 4(22): 4399-4428 (doi: 10.1002/ece3.1305).

5. Tan C., Bian C., Yang D., Li N., Wu Z.-F., Hu X.-X. Application of genomic selection in farm animal breeding. Yi Chuan, 2017, 39(11): 1033-1045 (doi: 10.16288/j.yczz.17-286).

6. Weigend S., Romanov M.N. The world watch list for domestic animal diversity in the context of conservation and utilisation of poultry biodiversity. World's Poultry Science Journal, 2002, 58(4): 411-430 (doi: 10.1079/WPS20020031).

7. Groeneveld L.F., Lenstra J.A., Eding H., Toro M. A., Scherf B., Pilling D., Negrini R., Finlay E.K., Jianlin H., Groeneveld E., Weigend S., the GLOBALDIV Consortium. Genetic diversity in farm animals - a review. Animal Genetics, 2010, 41(s1): 6-31 (doi: 10.1111/j.13652052.2010.02038.x).

8. Soller M., Weigend S., Romanov M.N., Dekkers J.C.M., Lamont S.J. Strategies to assess structural variation in the chicken genome and its associations with biodiversity and biological performance. Poultry Science, 2006, 85(12): 2061-2078 (doi: 10.1093/ps/85.12.2061).

9. Wilkinson S., Wiener P., Teverson D., C.S.Haley, Hjcking P.M. Characterization of the genetic diversity, structure and admixture of British chicken breeds. Animal Genetics, 2012, 43(5): 552563 (doi: 10.1111/j.1365-2052.2011.02296.x).

10. Reed K.M., Mendoza K.M., Beattie C.W. Comparative analysis of microsatellite loci in chicken and turkey. Genome, 2000, 43(5): 796-802.

11. Colombo E., Strillacci G., Cozzi M.C., Madeddu M., Mangiagalli M.G., Mosca F., Zaniboni L., Bagnato A., Cerolini S. Feasibility study on the FAO chicken microsatellite panel to assess genetic variability in the turkey (Meleagris gallopavo). Italian Journal of Animal Science, 2014, 13(4): 887-890 (doi: 10.4081/ijas.2014.3334).

12. Novgorodova I.P., Gladyr' E.A., Fisinin V.I., Zinov'eva N.A. Dostizheniya nauki i tekhniki APK, 2015, 29(11): 88-90 (in Russ.).

13. Novgorodova I.P., Volkova V.V., Gladyr' E.A., Selionova M.I., Rastovarov E.I., Fisinin V.I., Zinov'eva N.A. Dostizheniya nauki i tekhniki APK, 2011, 10: 66-67 (in Russ.).

14. Reed K.M., Chaves L.D., Garbe J.R., Da Y., Harry D.E. Allelic variation and genetic linkage of avian microsatellites in a new turkey population for genetic mapping. Cytogenetic and Genome Research, 2003, 102(1-4): 331-339 (doi: 10.1159/000075771). 
15. Reed K.M., Chaves L.D., Knutson T.P., Krueth S.B., Ashwell C.M., Burt D.W. Integration of microsatellite - based genetic maps for the turkey (Meleagris gallopavo). Genome, 2006, 49(10): 1308-1318 (doi: 10.1139/g06-084).

16. Smith E.J., Geng T., Long E., Pierson F.W., Sponenberg D.P., Larson C., Gogal R. Molecular analysis of the relatedness of five domesticated turkey strains. Biochemical Genetics, 2005, 43(12): 35-47 (doi: 10.1007/s10528-005-1065-5).

17. Fisinin V.I., Selionova M.I., Shinkarenko L.A., Shcherbatova N.G., Kononova L.V. Study of microsatellites in the Russian breeds of turkey. Sel'skokhozyaistvennaya biologiya [Agricultural Biology], 2017, 52(4): 739-748 (doi: 10.15389/agrobiology.2017.4.739eng).

18. Reed K.M., Chaves L.D., Rowe J.A. Twelve new turkey microsatellite loci. Poultry Science, 2002, 81(12): 1789-1791 (doi: 10.1093/ps/81.12.1789).

19. Reed K.M., Roberts M.C., Murtaugh J., Beattie C.W., Alexander L.J. Eight new dinucleotide loci in turkey (Meleagris gallopavo). Animal Genetics, 2000, 31(2): 140-157 (doi: 10.1046/j.13652052.2000.00571.x).

20. Peakall R., Smouse P.E. GenAIEx 6.5: genetic analysis in Excel. Population genetic software for teaching and research - an update. Bioinformatics, 2012, 28(19): 2537-2539 (doi: 10.1093/bioinformatics/bts460).

21. Weir B.S., Cockerham C.C. Estimating F-statistics for the analysis of population structure. Evolution, 1984, 38(6): 1358-1370 (doi: 10.2307/2408641).

22. Nei M. Genetic distance between populations. American Naturalist, 1972, 106: 283-392.

23. Falush D., Stephens M., Pritchard J.K. Inference of population structure using multilocus genotype data: linked loci and correlated allele frequencies. Genetics, 2003, 164(4): 1567-1587.

24. Latch E.K., Smith E.J., Rhodes O.E. Isolation and characterization of microsatellite loci in wild and domestic turkeys (Meleagris gallopavo). Molecular Ecology Note, 2002, 2(2): 176-178 (doi: 10.1046/j.1471-8286.2002.00183.x).

25. Kusza S., Mihók S., Czeglédi L., Javor A., Arnyasi M. Testing the breeding strategy of Hungarian Bronze turkey strains for maintaining genetic diversity with microsatellites. Arch. Anim. Breed., 2011, 54(4): 419-429 (doi: 10.5194/aab-54-419-2011).

26. Shinkarenko L.A., Terletskii V.P., Tyshchenko V.I. Ptitsevodstvo, 2020, 9: 17-21 (doi: 10.33845/0033-3239-2020-69-9-17-21) (in Russ.).

27. Kamara D., Gyenai K.B., Geng T., Hammade H. Microsatellite marker-based genetic analysis of relatedness between commercial and heritage turkeys (Meleagris gallopavo). Poultry Science, 2007, 86(1): 46-49 (doi: 10.1093/ps/86.1.46).

28. Knutson T.P., Chaves L.D., Hall M.K., Reed K.M. One hundred fifty-four genetic markers for the turkey (Meleagris gallopavo). Genome, 2004, 47(6): 1015-1028 (doi: 10.1139/g04-076).

29. Mock K.E., Theimer T.C., Rhodes O.E., Greenberg D.L., Keim P. Genetic variation across the historical range of the wild turkey (Meleagris gallopavo). Molecular Ecology, 2002, 11(4): 643657 (doi: 10.1046/j.1365-294X.2002.01467.x).

30. Aslam M.L., Bastiaansen J.W.M., Elferink M.G, Megens H.J., Crooijmans R.P.M.A., Blomberg L.A., Fleischer R.C., Tassell C.P., Sonstegard T.S., Schroeder C.G., Groenen M.A.M, Long J.A. Whole genome SNP discovery and analysis of genetic diversity in Turkey (Meleagris gallopavo). BMC Genomics, 2012, 13: 391-404 (doi: 10.1186/1471-2164-13-391).

31. Flicek P., Amode M.R., Barrell D., Beal K., Brent S., Carvalho-Silva D., Clapham P., Coates G., Fairley S., Fitzgerald S., Gil L., Gordon L., Hendrix M., Hourlier T., Johnson N., Кдһдri А. K., Keefe D., Keenan S., Kinsella R., Komorowska M., Koscielny G., Kulesha E., Larsson P., Longden I., McLaren W., Muffato M., Overduin M.M.B., Pignatelli M., Pritchard B., Riat H.S., Ritchie G., Ruffier M., Schuster M.R.B., Sobral D., Tang A., Taylor T., Trevanion S., Vandrovcova J., White S.J., Wilson M., Wilder S.P., Aken B.L., Birney E., Cunningham F., Dunham I., Durbin R., Fernandez-Suarez X., Harrow J., Herrero J., Hubbard T., Parker A., Proctor G., Spudich G., Vogel J., Yates A., Zadissa A., Searle S. Ensembl 2012. Nucleic Acids Research. 2012, 40(D1): D84-D90 (doi: 10.1093/nar/gkr991).

32. Dalloul R. A., Long J.A., Zimin A.V., Aslam L., Beal K., Blomberg L. A., Bouffard P., Burt D.W., Crasta O., Crooijmans R.P.M.A., Cooper K., Coulombe R.A., De S., Delany M.E., Dodgson J.B., Dong J.J., Evans C., Frederickson K.M., Flicek P., Florea L., Folkerts O., Groenen M.A.M., Harkins T., Herrero J., Hoffmann S., Megens H.-J., Jiang A., Jong P., Kaiser P., Kim H., Kim K-W., Kim S., Langenberger D., Lee M-K., Lee T., Mane S., Marcais G., Marz M., McElroy A., Modise T., Nefedov M., Notredame C., Paton I.R., Payne W.S., Pertea G., Prickett D., Puiu D., Qioa D., Raineri E., Ruffier M., Salzberg S.L., Schatz M.C., Scheuring C., Schmidt C.J., Schroeder S., Searle S.M.J., Smith E.J., Smith J., Sonstegard T.S., Stadler P.F., Tafer H., Tu Z.J., Tassell C.P., Vilella A.J., Williams K.P., Yorke J.A., Zhang L., Zhang H.-B., Zhang X., Zhang Y., Reed K.M. Multi-platform nextgeneration sequencing of the domestic turkey (Meleagris gallopavo): Genome Assembly and Analysis. PLoS Biology, 8(9): e1000475 (doi: 10.1371/journal.pbio.1000475). 